\title{
Thermal Performance of Wet Cooling Tower with Grid Fill
}

\author{
Pavol Vitkovic, Lukas Dvorak \\ Czech Technical University in Prague \\ Technicka 4, Prague, Czech Republic \\ pavol.vitkovic@fs.cvut.cz; 1.dvorak@fs.cvut.cz
}

\begin{abstract}
Cooling towers are evaporative heat rejection devices, which take out the waste heat from a process to the atmosphere through the cooling of water by the ambient air. The cooling tower is basically a mixed heat exchanger. A spray zone, fill zone and a rain zone are three important zones from heat and mass transfer view in the cooling tower. Thermal performances of all these zones are obtained by experimental measurements due complicated heat and mass transfer phenomena in a cooling tower. The spray zone and fill zone was measured together. And the thermal performance of rain zone was evaluated.
\end{abstract}

Keywords: cooling tower, heat exchanger, fill zone, rain zone, Merkel number

\section{Introduction}

We can divide a cooling tower into three principal zones from heat and mass transfer view. There are a spray zone, a fill zone and a rain zone. The first one is consist of small water formation created by spray nozzles. The spray nozzles are used to distribute water in a wet cooling tower. The second one is fill zone. For the cooling tower are used a film fill or splash fill in the general. The Grid fill is a member of splash fills family using in cooling tower [1]. It has lower heat transfer performance like the film fill usually. But their advantage is great resistance to blockage the fill operation by impurities. The fill zone is the main part of heat and mass transfer between cooled water and ambient air. Water formation comes out from the fill and it creates rain zone. Many studies reporting an experimental investigation of the thermal performance of cooling tower (fill zone, spray zone, rain zone) [2-8].

\section{Methods}

The counter-flow cooling tower test cell is described in [9] was used for experimental measurement. The testing cell has a water and an air circuit. The test cross-section area is $1.47 \mathrm{~m} \mathrm{x} 1.47 \mathrm{~m}$. The height of the test facility is $5 \mathrm{~m}$. Each position of probes is shown in Fig. 1.
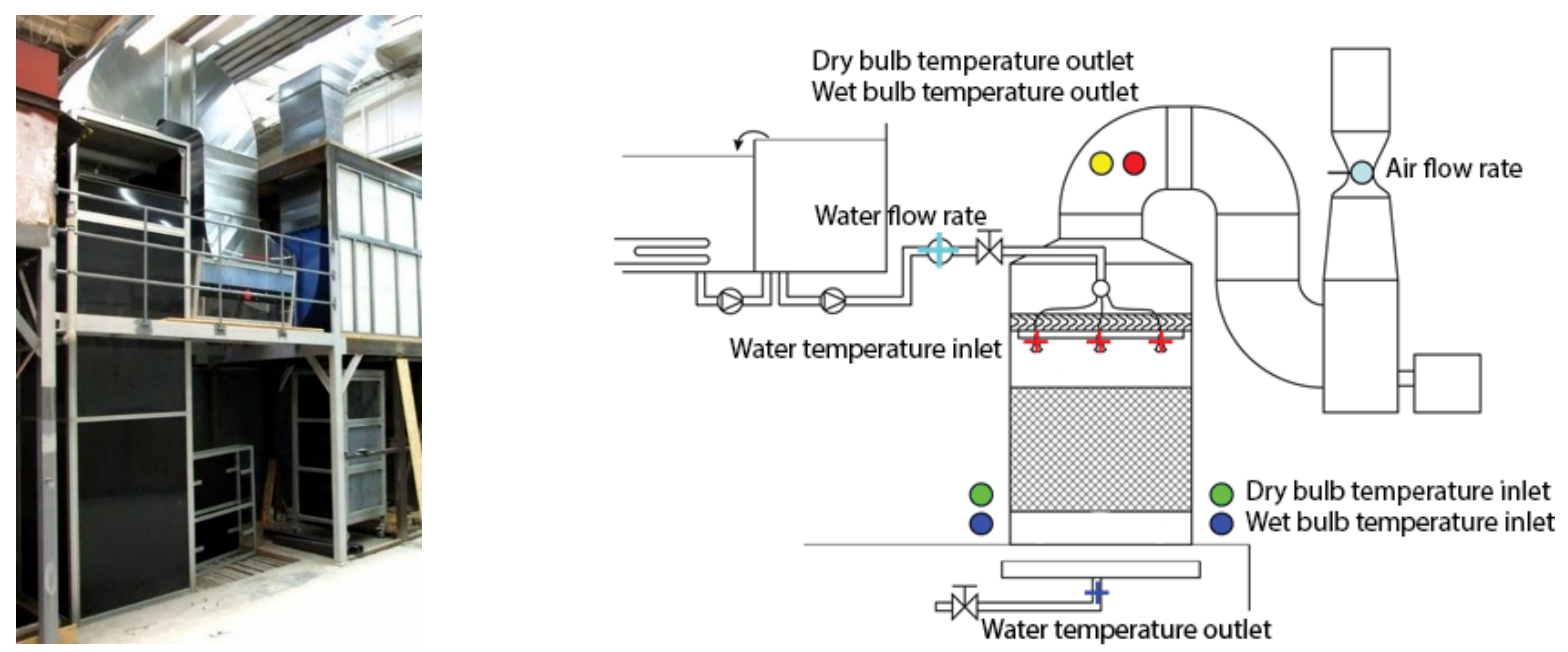

Fig. 1: Counter-flow cooling tower test cell. 
The fill zone thermal performance measurement has followed conditions (Fig. 2 left schematic). As the cooling fill was used the Grid fill with the rhombus shape bars. The side length of the rhombus is $53 \mathrm{~mm}$ and the thickness of bar is $5 \mathrm{~mm}$.
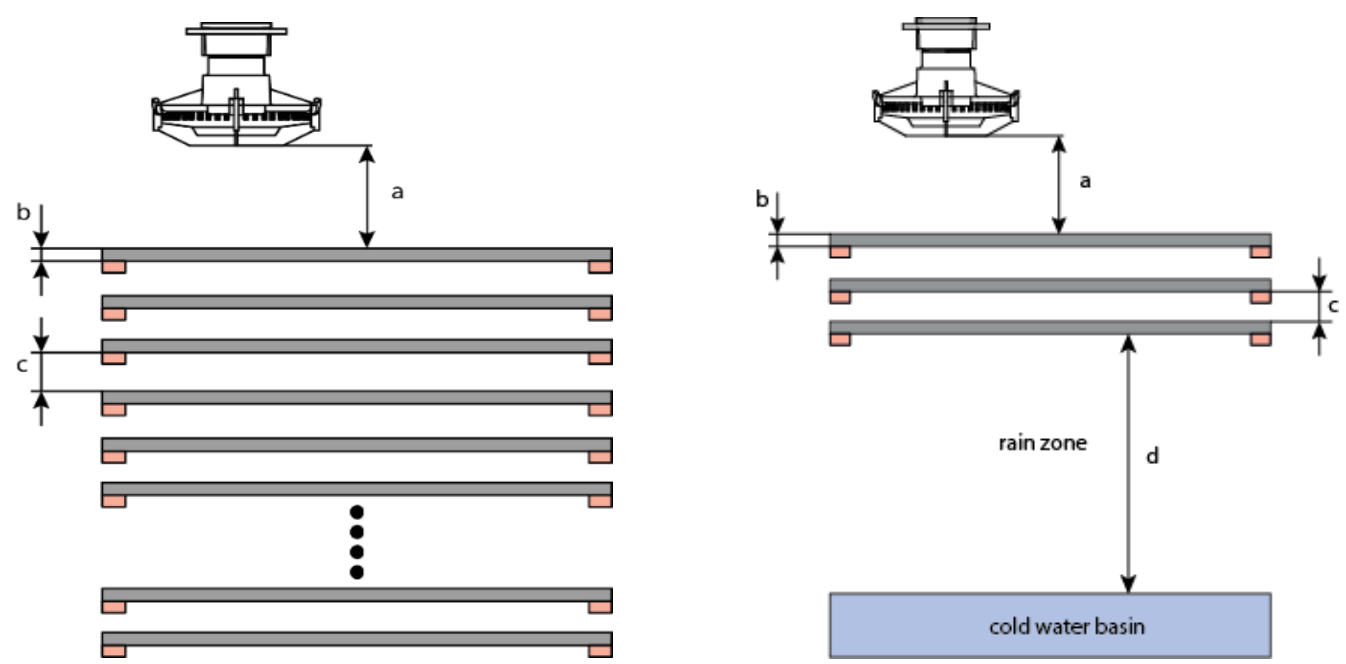

Fig. 2: Fill zone measurement setup (left) $(a=0.6 \mathrm{~m}, \mathrm{~b}=0,024 \mathrm{~m}, \mathrm{c}=0.44 \mathrm{~m}$; and Rain zone measurement setup (right) $(\mathrm{a}=0.15 \mathrm{~m}, \mathrm{~b}$ $=0,024 \mathrm{~m}, \mathrm{c}=0.22 \mathrm{~m}, \mathrm{~d}=1.45,1.98,3.03 \mathrm{~m})$.

The rain zone thermal performance measurement has needed different configuration in the test cell (Fig. 2 right schematic). The distance between the spray nozzles and fill face was $0.15 \mathrm{~m}$. The fill spacing was $0.22 \mathrm{~m}$. This distance is different from the fill zone measurement setup. The rain zone measurement setup was designed for maximum rain zone operate range. The rain zone generator was consisting spray nozzle and the three layers of Grid fills. During the experiment was set up three different height of the rain zone $(1.45 \mathrm{~m}, 1.98 \mathrm{~m}$ and $3.03 \mathrm{~m})$.

From the measured data was evaluated Merkel number (1) by the Chebyshev methods [1]. Where $K$ is mass transfer coefficient, $a$ is contact area, $V$ is active cooling volume, $L$ is water loading, $c$ is specific heat of water, $T_{l}$ is hot water temperature, $T_{2}$ is cold water temperature, $h_{a s}$ is enthalpy of air-water vapour mixture at bulk water temperature, $h_{a}$ is enthalpy of air-water vapour mixture at wet bulb temperature. The results were plotted as a graph of Merkel number against the proportion of the mass flow of water and air (ratio $L / G$ ).

$$
M e=\frac{K a V}{L}=c \int_{T_{2}}^{T_{1}} \frac{d T}{h_{s a}-h_{a}}
$$

\section{Results}

For the measurement of the fill zone was used from 4 to 7 layers of Grid fill. The fit surface (Fig. 3) creates the fit to the data in ratio $L / G$ and fills height $h$. The expression for the Merkel number calculation is follows

$$
M e_{\text {fill zone }}=0.3672 \cdot(L / G)^{-0.2794} \cdot h^{0.7}
$$

This expression is for the fill zone with a variable height of fill layers. Where $h[\mathrm{~m}]$ is the height of the fill zone. Two layers of Grid fill represents $0.44 \mathrm{~m}$ of the height of the fill zone.

For rain zone (Fig. 4 and Fig. 5) was evaluated a similar expression like for fill zone.

$$
M e_{\text {rain zone }}=0.066 \cdot(L / G)^{-0.3684} \cdot H
$$

where $H[\mathrm{~m}]$ is the height of the rain zone. In this case, exponent over the $H$ was 0.98 . It is nearly linear dependence. In final expression was used exponent 1 . In this case, was measured the rain zone and the fill zone like a rain zone generator together. From these measurements is subtracted the fill zone. 

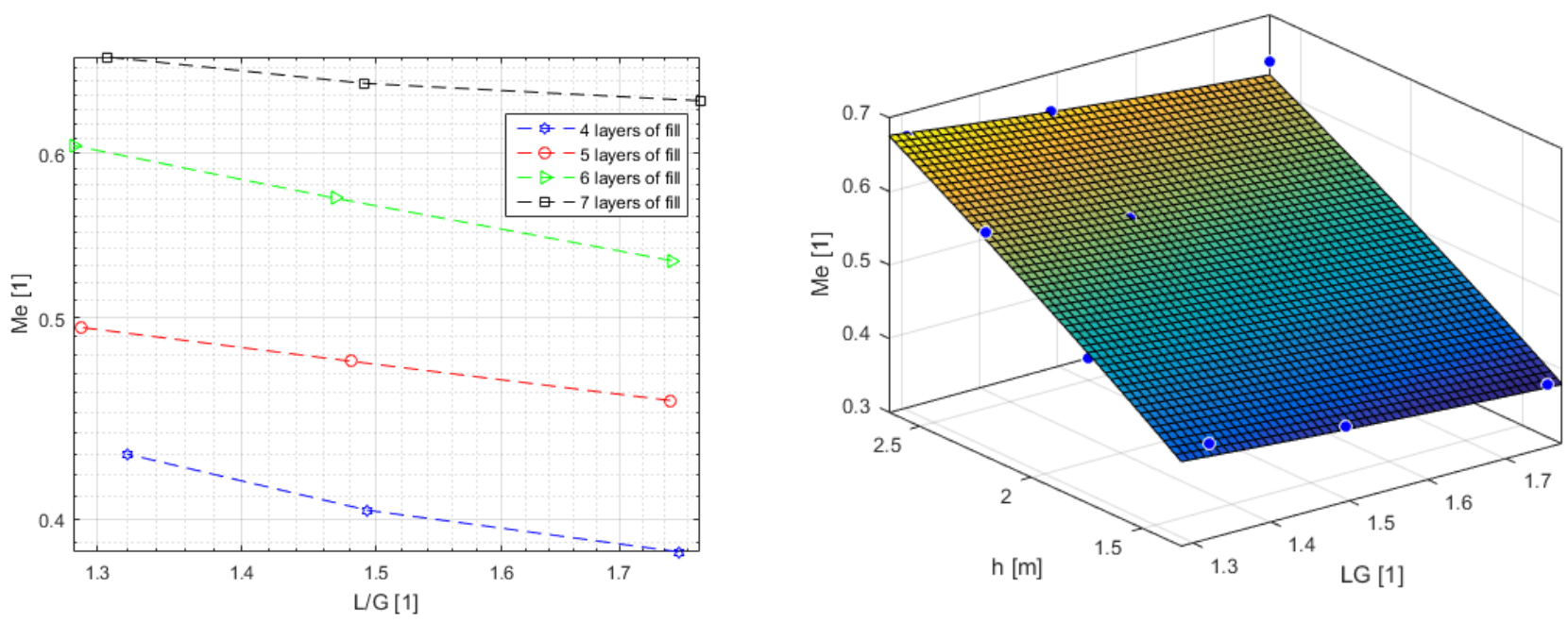

Fig. 3: Merkel number and ratio L/G depend on the fills height.
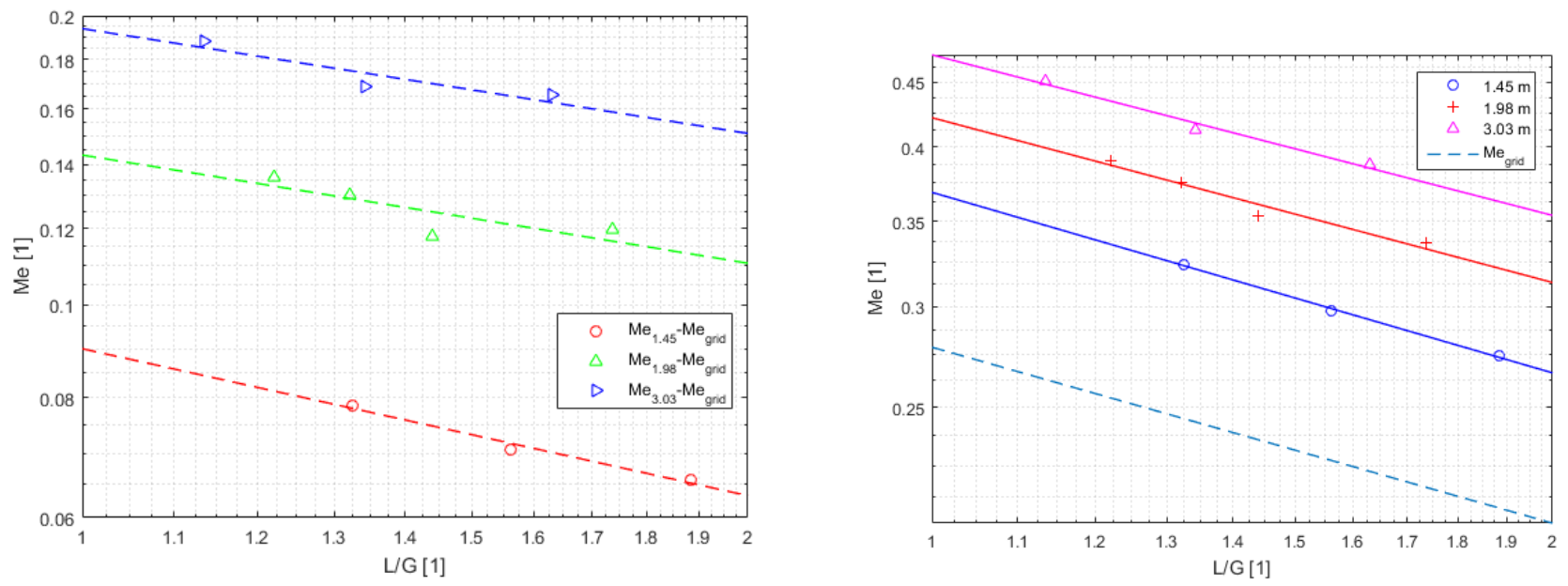

Fig. 4: Merkel number of rain zone.

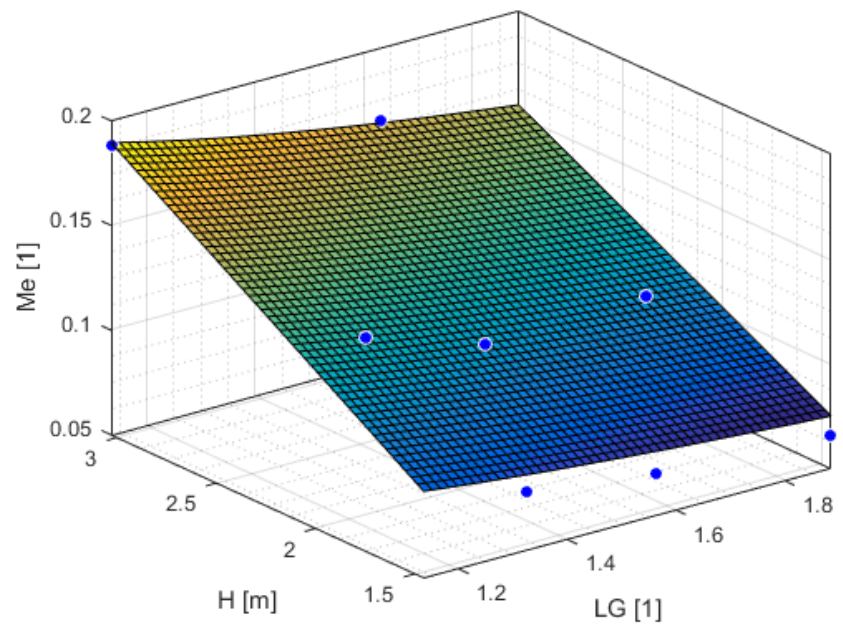

Fig. 5: Merkel number and ratio $\mathrm{L} / \mathrm{G}$ depend on the rain zone height. 


\section{Discussion and Conclusion}

In Fig. 6 are 12 combinations of the different height of fill zone and rain zone. It shows that the main part of heat and mass transfer in the fill zone. Total height (fill zone and rain zone) is $5 \mathrm{~m}$ for all combinations.

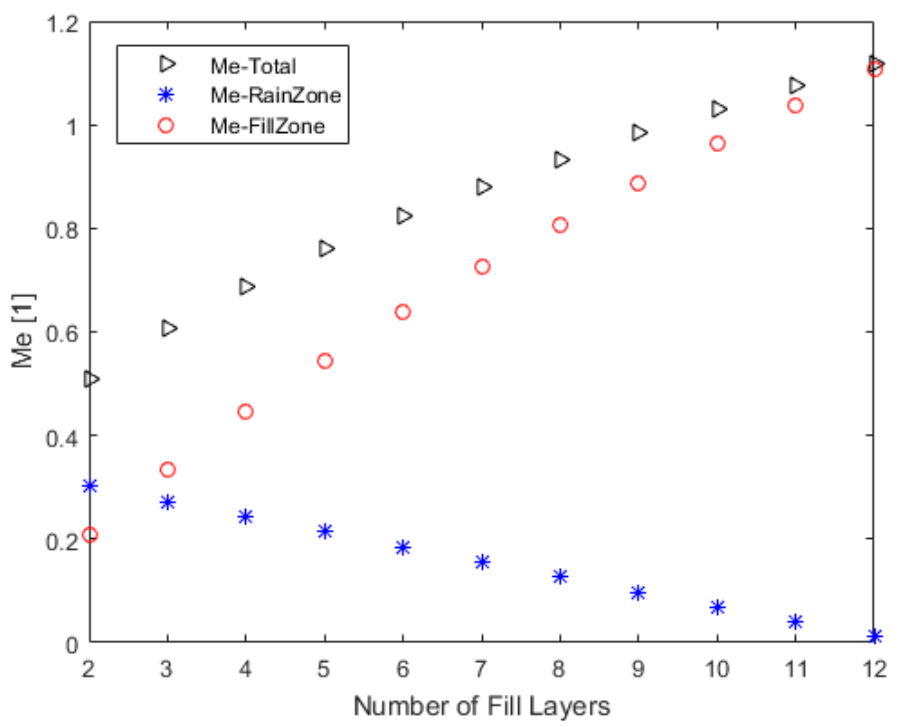

Fig. 6: Merkel number calculation for different number of fill layers in the cooling tower.

We obtained useful data for calculation of Merkel numbers for two important parts of the cooling tower, during the experimental tests. The first one was the fill zone. It is the main part of heat and mass transfer in a cooling tower. The second one was a rain zone. The second largest part of heat and mass transfer in a cooling tower. The Merkel number was evaluated for both critical regions in a cooling tower. The three layers are the critical number, where is changing main heat and mass transfer from the rain zone to the fill zone.

\section{Acknowledgements}

The authors acknowledge the support received from Advanced Technologies for Heat and Electricity Production TE01020036 and Centre for Research on Multiphase Flow and Thermodynamics Processes in Renewable Sources and Energetics - NEW ENERGY supported by the European Union (reg. n. CZ.2.16/3.1.00/22130).

\section{References}

[1] D. G. Kroger, Air-Cooled Heat Exchangers and Cooling Towers. PennWell, 2004.

[2] H. R. Goshayshi and J. F. Missenden, "The investigation of cooling tower packing in various arrangements," Applied Thermal Engineering, vol. 20, no. 1, pp. 69-80, 2000.

[3] F. Gharagheizi, R. Hayati, and S. Fatemi, "Experimental study on the performance of mechanical cooling tower with two types of film packing," Energy Conversion and Management, vol. 48, no. 1, pp. 277-280, 2007.

[4] H. C. Reuter and D. G. Kröger, "Effects of wettability on the performance of cross-fluted counterflow film fill and the drop size distribution under the fill," in 13th IAHR Cooling Tower Conference, Poitier, 2005.

[5] H. C. Reuter, D. J. Viljoen, and D. G. Kröger, "Evaluation and performance prediction of cooling tower spray zones," Africomp, 2009.

[6] R. K. Singla, K. Singh, and R. Das, "Tower characteristics correlation and parameter retrieval in wet- cooling tower with expanded wire mesh packing," Applied Thermal Engineering, vol. 96, pp. 240-249, 2016.

[7] H. C. Reuter and D. G. Kröger, "Evaluation and performance prediction of cooling tower spray zones," in ASME IHTC, Washington, 2010.

[8] R. Terblanche, H. C. Reuter, and D. G. Kröger, "Drop size distribution and performance prediction in a rain zone test facility," in 14th IAHR Cooling Tower and Air-cooled Heat Exchanger Conference, Stellenbosch, 2009.

[9] L. Dvorak and J. Nozicka, "Counter-Flow Cooling Tower Test Cell,” in EPJ Web of Conferences, vol. 67, 2014. 